\title{
Thermal Radiation Effects on Unsteady Stagnation Point Nanofluid Flow in View of Convective Boundary Conditions
}

\author{
Haroon Ur Rasheed $\left({ }^{1},{ }^{1}\right.$ Saeed Islam, ${ }^{1}$ Zeeshan Khan, ${ }^{2}$ Sayer O. Alharbi, ${ }^{3}$ Waqar A Khan, ${ }^{4}$ \\ Waris Khan $\mathbb{D D}^{5}$ and Ilyas Khan ${ }^{3}{ }^{3}$ \\ ${ }^{1}$ Department of Mathematics, Abdul Wali Khan University Mardan, Mardan 23200, Khyber Pakhtunkhwa, Pakistan \\ ${ }^{2}$ Sarhad University of Science and Information Technology, Peshawar 25000, Khyber Pakhtunkhwa, Pakistan \\ ${ }^{3}$ Department of Mathematics, College of Science Al-Zulfi, Majmaah University, Al-Majmaah 11952, Saudi Arabia \\ ${ }^{4}$ Department of Mechanical Engineering, Prince Mohammad Bin Fahd University, P. O. Box 1664, Al Khobar 31952, \\ Saudi Arabia \\ ${ }^{5}$ Department of Mathematics and Statistics, Hazara University Mansehra, Mansehra, Khyber Pakhtunkhwa, Pakistan
}

Correspondence should be addressed to Ilyas Khan; ilyaskhan@tdtu.edu.vn

Received 11 February 2021; Revised 15 April 2021; Accepted 12 June 2021; Published 21 June 2021

Academic Editor: Carlos Llopis-Albert

Copyright (c) 2021 Haroon Ur Rasheed et al. This is an open access article distributed under the Creative Commons Attribution License, which permits unrestricted use, distribution, and reproduction in any medium, provided the original work is properly cited.

\begin{abstract}
The present communication particularizes nonlinear convective non-Newtonian stagnation point flow and heat transference effects in stretchable flow of nanofluid. Magnetohydromagnetic steady viscous flow of nanofluid is examined. Heat transfer attributes of nanofluids are addressed via a numerical algorithm. Conductivity and diffusivity characteristics of fluid are depending on temperature and concentration and furthermore, on mass conservation, momentum, energy, and concentration yield partial differential equations (PDEs). The boundary layer flow concept pioneered by Prandtl has been employed to simplify the nonlinear constitutive flow laws which are then changed to ordinary differential equations. A built-in bvp4c algorithm in Mathematica software yields convergent outcomes of nonlinear (ODEs) systems. A comprehensive analysis has been made elucidating the physical significance of various governing parameters effects presented graphically. Additionally, the flow nature was confirmed versus streamlines.
\end{abstract}

\section{Introduction}

The low thermal conductivity features of various nonNewtonian fluids have serious problems with heat transport mechanisms in different scientific and practical engineering applications. Several attempts have been made by researchers and engineers to address the low thermal behavior of the base fluids. Different tools and mechanisms have been adopted for the enhancement of thermal conductivity issues. Out of these suggested mechanisms, incorporating small nanosized metallic particles into base fluid yields potential results. The word nanofluid was adopted by Choi and Eastman [1]. Khan et al. [2] discussed fluid thermal conductivity features by utilizing nanofluid for the development of heat transportation analysis for various applications in different heat exchanger equipment. There are many important applications and narrative characteristics of nanofluids in various applications in engineering and industrial units. These nanofluid applications include heat exchange processes such as chillers, nuclear power stations, car engines, microelectronics, fuel cells, coolant, and many more engineering utilization as discussed by Turkyilmazoglu [3]. The nanofluid has significant advantages and applications in manufacturing industries. A great number of mathematicians, researchers, and scientists addressed such utilizations of nanofluid for development in [4-10]. For the first time, Hiemenz [11] conducted extensive research and discussed the exact solution to stagnation point flow by NavierStokes's equation. Furthermore, stagnation point flow was investigated, which can be steady or unsteady, normal or 
oblique, two or more dimensional, onward or opposite, and viscous or inviscid. Khan et al. [12] elucidated different aspects of unsteady non-Newtonian stagnation point nanofluid flow and multiple solutions analyzed and furthermore, added the enhancement of thermal behavior of the base fluid by incorporating the nanofluid. A potential investigation has been made to analyze three-dimensional stagnation point hybrid nanofluid flow over a slip surface by Abbas et al. [13]. Serious attention has been given in recent times by researchers, engineers, and mathematicians to explore non-Newtonian stagnation point flow nanofluid flow [14-17]. The viscoelastic nanofluids have a variety of practical usage in daily life and large-scale applications. Such important utilizations of non-Newtonian fluids are foods, multiphase mixtures molecular weight systems, and various solutions. Abbas et al. [18] studied stagnation point MHD flow and thermal radiation effects on micropolar flow past through a round cylinder with sinusoidal radius variation. Furthermore, porosity influence and velocity slip jump are evaluated. Akbar et al. [19] explored hydromagnetic convective condition along with slip effects on stagnation point nanofluid by incorporation of CNT particles past a stretchable surface, and thermal radiations have been analyzed. Moreover, the convective boundary conditions with slip flow and incorporated CNT nanofluid vied in a stretchable plane surface. Those materials showing non-Newtonian fluid flow features contain the natural products, food products, polymer melts and solutions, biological fluids, multiphase mixtures, and personal care products including investigated toiletries and cosmetics and by Ijaz et al. [20]. The non-Newtonian fluids have a great number of significant utilizations in industrial units, medical technologies, and engineering application. The expanding uses of these nanofluids describe petroleum drilling, steel substances, blasting of glasses, and extrusion of polymers. Some of the polymers employed in telecommunication appliances, agriculture, and medical are analyzed by Hussain et al. [21]. Muhammad et al. [22] investigated nonlinear thermal radiation in three-dimensional Eyring-Powell nanofluid flow with activation energy. Hussain and Muhammad [23] discussed convective heat transfer at the boundaries is incorporated by employing effective thermal conductivity of nanoliquid. Muhammad et al. [24] studied Carreau nanofluid under the influence of slip over a wedge with motile microorganisms and thermal radiation effects. Besides, these many scientists carried to analyze the stagnation point flow and other nonNewtonian fluids with aspect to the following citations, provided a detailed view of flows [25-33].

\section{Mathematical Formulation}

Here, we formulate unsteady non-Newtonian stagnation point stretchable flow of incompressible viscous nanofluid along with convection boundary conditions. Lower surface of sheet heated convectively fluid having temperature $\left(T_{f}\right)$ and heat transportation transfer coefficient $\left(h_{f}\right)$ and the ambient fluid having temperature $\left(T_{\infty}\right)$ and concentration $\left(C_{\infty}\right)$, respectively. The stretchable sheet velocity at the surface is defined by the relation $u_{w}(x)=a x^{n}$, where $a$ is the fixed positive constant. Magnetic field source is adequate with strength $\left(B_{0}\right)$ positioned in $(+\mathrm{ve}) y$ direction normal to stretchable surface for magnetization. The influence of induced magnetic properties is small with respect to the applied one and is neglected. Furthermore, there is a thermal equilibrium to base fluid and suspended nanoparticles. Flow diagram and coordinate axes are shown in Figure 1. Boundary layer governs flow expressions by

Mass conservation expression:

$$
\frac{\partial u}{\partial x}+\frac{\partial v}{\partial y}=0
$$

Momentum expression:

$$
u \frac{\partial u}{\partial x}+v \frac{\partial u}{\partial y}=v \frac{\partial^{2} u}{\partial y^{2}}+U_{\infty} \frac{\partial U_{\infty}}{\partial x}+\frac{\sigma B_{0}^{2}}{\rho_{f}}\left(U_{\infty}-u\right)
$$

Energy expression:

$$
u \frac{\partial T}{\partial x}+v \frac{\partial T}{\partial y}=\alpha\left(\frac{\partial^{2} T}{\partial y^{2}}\right)+\Gamma\left(D_{B} \frac{\partial C}{\partial y} \frac{\partial T}{\partial y}+\frac{D_{T}}{T_{\infty}}\left(\frac{\partial T}{\partial y}\right)^{2}\right)
$$

Concentration of nanoparticles:

$$
u \frac{\partial C}{\partial x}+v \frac{\partial C}{\partial y}=D_{B}\left(\frac{\partial^{2} C}{\partial y^{2}}\right)+\frac{D_{T}}{T_{\infty}}\left(\frac{\partial^{2} T}{\partial y^{2}}\right)
$$

Subject to flow conditions are as follows:

$$
\begin{aligned}
u & =u_{w}(x)=a x, \\
v & =0, \\
-k \frac{\partial T}{\partial y} & =h_{f}\left(T_{f}-T\right), \\
D_{B} \frac{\partial C}{\partial y}+\frac{D_{T}}{T_{\infty}}\left(\frac{\partial T}{\partial y}\right) & =0, \quad \text { for } y=0, \\
u \longrightarrow U_{\infty} & =b x, \\
v & =0, \\
T & \longrightarrow T_{\infty}, \\
C & \longrightarrow C_{\infty}, \quad \text { for } y=\infty .
\end{aligned}
$$

Herein, $u$ and $v$ velocity components are in coordinates axes, along and normal to flow direction

The kinematics viscosity is $v$, inside boundary layer temperature is $T$, nanoparticles effective heat capacity is $(\rho c)_{p}$, thermal capacity of fluid is $(\rho c)_{f}$, fluid density is $(\rho), \Gamma=\left((\rho c)_{p} /(\rho c)_{f}\right)$, and $T_{\infty}$ is the ambient temperature away from stretchable surface.

Introducing dimensionless parameters, 


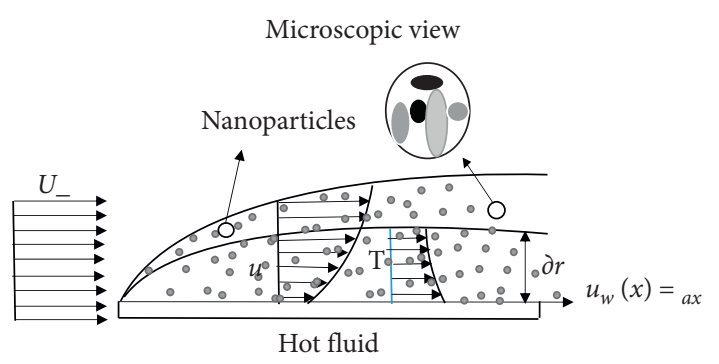

FIgURE 1: Flow geometry.

$$
\begin{aligned}
\eta & =\sqrt{\frac{a}{v} y,} \\
\psi & =\sqrt{\operatorname{av}} \times f(\eta), \\
\theta(\eta) & =\frac{T-T_{\infty}}{T_{f}-T_{\infty}}, \\
\phi(\eta) & =\frac{C-C_{\infty}}{C_{\infty}} .
\end{aligned}
$$

Here, the stream function $\psi(x, y)$ is defined by

$$
\begin{aligned}
& u=\frac{\partial \psi}{\partial y} \\
& v=-\frac{\partial \psi}{\partial x}
\end{aligned}
$$

Equation (1) is justified automatically, and equations (2)-(4) take the following forms by employing equation (6):

$$
\begin{aligned}
f^{\prime \prime \prime}+f f^{\prime \prime}-\left(f^{\prime}\right)^{2}+A^{2}+M\left(A-f^{\prime}\right) & =0, \\
\frac{1}{\operatorname{Pr}} \theta^{\prime \prime}+f \theta^{\prime}+N b \phi^{\prime} \theta^{\prime}+N t\left(\theta^{\prime}\right) & =0, \\
\phi^{\prime \prime}+\operatorname{Le} \operatorname{Pr} f \phi^{\prime}+\frac{N t}{N b} \theta^{\prime \prime} & =0 .
\end{aligned}
$$

Transformed conditions:

$$
\begin{aligned}
f(0) & =0, \\
f^{\prime}(0) & =1, \\
\theta^{\prime}(0) & =\operatorname{Bi}(\theta(0)-1), \\
N b \phi^{\prime}(0)+N t \theta^{\prime}(0) & =0, \\
f^{\prime}(\infty) & =A, \\
\theta(\infty) & =0, \\
\phi(\infty) & =0 .
\end{aligned}
$$

Variables seeming in constitutive flow laws (8)-(11) are defined as follows:

$M=\left(\sigma B_{0}^{2} / \rho_{f} a\right)$, the magnetic parameter; Le $=\left(\alpha / D_{B}\right)$, Lewis number; $\operatorname{Pr}=(v / \alpha)$, Prandtl number; $A=(b / a)$, velocity ratio parameter; $N b=\left((\rho c)_{p} D_{B} C_{\infty} /(\rho c)_{f} v\right)$,
Brownian motion parameter; $N t=\left((\rho c)_{p} D_{T}\left(T_{f}\right.\right.$ $\left.\left.T_{\infty}\right) /(\rho c)_{f} v T_{\infty}\right)$, thermophoresis parameter; and $\mathrm{Bi}=$ $\sqrt{v / a}\left(h_{f} / k\right)$, Biot number, respectively.

Expressions of physical quantities $\left(C f_{x}, N u_{x}\right)$ are defined by

$$
\begin{aligned}
C f_{x} & =\frac{\tau_{w}}{\rho u_{w}^{2}}, \\
N u_{x} & =\frac{x q_{w}}{k\left(T_{f}-T_{\infty}\right)} . \\
\tau_{w} & =\left.\mu\left(\frac{\partial u}{\partial y}\right)\right|_{\text {at } y=0}, \\
q_{w} & =-\left.k\left(\frac{\partial T}{\partial y}\right)\right|_{\text {at } y=0} .
\end{aligned}
$$

By substituting (13) in (12), we have

$$
\begin{aligned}
\operatorname{Re}_{x}^{0.5} C f_{x} & =-f^{\prime \prime}(0) \\
\operatorname{Re}_{x}^{-0.5} N u_{x} & =-\theta^{\prime}(0) .
\end{aligned}
$$

\section{Numerical Solution and Convergence Analysis}

For numerical solution, the $1^{\text {st }}$ order differential equations are found from equations (8)-(10) by introducing the following transformations relations. Let the transformations variables be defined by

$$
\begin{aligned}
f(\eta) & =x_{1}, \\
f^{\prime}(\eta) & =x_{2}, \\
f^{\prime \prime}(\eta) & =x_{3}, \\
\theta(\eta) & =x_{4}, \\
\theta^{\prime}(\eta) & =x_{5}, \\
\phi(\eta) & =x_{6}, \\
\phi^{\prime}(\eta) & =x_{7} .
\end{aligned}
$$

Following are the first-order differential equations generated:

$$
\begin{aligned}
& x_{1}^{\prime}=x_{2}, \\
& x_{2}^{\prime}=x_{3}, \\
& x_{3}^{\prime}=\left[x_{2}^{2}-x_{1} x_{3}-A^{2}-M\left(A-x_{2}\right)\right], \\
& x_{4}^{\prime}=x_{5}, \\
& x_{5}^{\prime}=-\operatorname{Pr}\left[x_{1} x_{5}+N b x_{7} x_{5}+N t x_{5}^{2}\right], \\
& x_{6}^{\prime}=x_{7}, \\
& x_{7}^{\prime}=-\left[\operatorname{Le} \operatorname{Pr} x_{1} x_{7}+\frac{N t}{N b} x_{5}^{\prime}\right] .
\end{aligned}
$$

The initial boundary conditions are 


$$
\begin{aligned}
x_{1}(0) & =0, \\
x_{2}(0) & =1, \\
x_{5}(0) & =\operatorname{Bi}\left(x_{4}(0)-1\right), \\
N b x_{7}(0)+N t x_{5}(0) & =0 \\
x_{2}(\infty) & =A, \\
x_{4}(\infty) & =0, \\
x_{6}(\infty) & =0 .
\end{aligned}
$$

A suitable step size $\Delta \eta=0.001$ is selected for the entire numerical computation work. A possible convergence limit has been adopted as $10^{-6}$. Furthermore, the boundary conditions given in (11) value at infinity is chosen as $\eta_{\infty}=4$; after selecting the appropriate value for $\eta_{\infty}$, all numerical solutions converge to it and are satisfied correctly. Finally, residual error analysis has been evaluated. Dwindles in error perceive for higher order deformations as shown in Figure 2. Furthermore, the algorithm of bvp4c routine calculation is shown in Figure 3.

\section{Results and Discussion}

The constative flow laws of nonlinear differential systems consisting of (8)-(10) subjected to specified boundary are solved numerically by employing the bvp4c algorithm. The attributes of affective pertinent flow factors on velocity field, thermal field, and nanoparticles volume are evaluated graphically and discussed in Figures 4-25.

Figures 4 and 5 depict variations in $f^{\prime}(\eta)$ velocity subjected to velocity ratio parameter $(A)$. These figures unveil enhancement in boundary layer thickness for higher $(A)$, perceive when $(A>1)$, and diminish the hydromagnetic boundary layer thickness for lower values of $(A)$ when $(A<1)$. In reality, stretching velocity is less than the free stream velocity, due to which the ratio of stretching velocity to free stream velocity is less than unity; consequently, decreasing force vanishes, and clearly, $f^{\prime}(\eta)$ profile is augmented. Attributes of $(M)$ are shown in Figure 6. Herein, we noticed $f^{\prime}(\eta)$ is lower subjected to increment in magnetic field. Such scenario found due to higher $(M)$ implies strong resistance force came into existence called Lorentz force. In consequence, dwindles in velocity $f^{\prime}(\eta)$ profile perceived. The contribution of the Prandtl number (Pr) on thermal field $\theta(\eta)$ is evaluated as shown in Figure 7 . The thermal diffusivity diminishes when (Pr) boosts through larger values. Hence, $\theta(\eta)$ decays. Consequently, thermal boundary layer thickness escalates. Figure 8 explains variations in $\theta(\eta)$ thermal field curves for the thermophoresis $(N t)$ parameter. This figure unveils enhancement in $\theta(\eta)$ when $(N t)$ is enlarged. In fact, nanoparticles attain extra heat subject to the $(N t)$ factor. In consequence, $\theta(\eta)$ upsurges. The temperature field $\theta(\eta)$ curves for the Biot number (Bi)

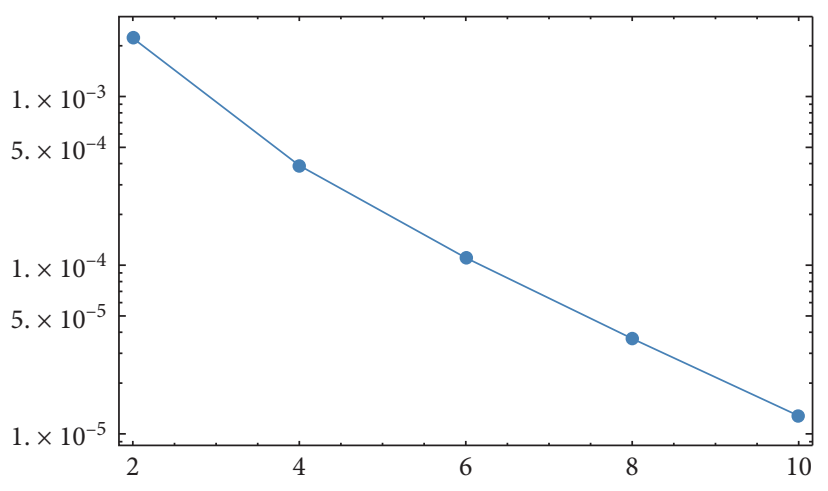

Figure 2: Total residual error via order of deformations.

also called convective heating are shown in Figure 9. One can clearly perceive that $\theta(\eta)$ is a growing function of $(\mathrm{Bi})$. In reality, heat transference at surface boosts through larger (Bi). Consequently, $\theta(\eta)$ upsurges. Hence, thermal boundary layer thickness escalates. Variations in temperature field $\theta(\eta)$ against $(A)$ are interprets as shown in Figure 10. Clearly, larger velocity ratio factor diminishes thermal boundary layer thickness.

Impact of concentration $\phi(\eta)$ profile against the $(\mathrm{Nb})$ parameter is portrayed as shown in Figure 11. This figure witnesses enhancement in $\phi(\eta)$. Clearly, $\phi(\eta)$ is an augmenting function of the Brownian motion parameter. In reality, one can observe heat transference boosts through larger $(N b)$. Consequently, $\phi(\eta)$ augments. Figure 12 discloses contribution of the $(N t)$ parameter on $\phi(\eta)$ profile. Clearly, dwindles $\phi(\eta)$ subject to increment in $(N t)$. Figure 13 shows the effects of Prandtl number (Pr) on concentration gradient. As the influence of the (Pr) parameter increases, nanoparticles diffuse outside which reduced the concentration at the surface. The contribution of Lewis number (Le) on the concentration profile is shown in Figure 14. An increasing value of the (Le) parameter shows a poor $(\mathrm{Nb})$ diffusion coefficient as a result of small penetration depth observed for $\phi(\eta)$ and displays decreasing trends in the concentration profile. The contribution of Boit number (Bi) parameter via $\phi(\eta)$ is shown in Figure 15. Clearly, larger estimations correspond to upsurges in the $\phi(\eta)$ profile. Figure 16 unveils $(A)$ velocity ratio factor influences on $\phi(\eta)$. It is viewed that the concentration $\phi(\eta)$ profile is a decreasing function of $(A)$. Such scenario is noticed because augmentation in $(A)$ yields reduction in fluid thermal conductivity. Consequently, $\phi(\eta)$ vanishes. Figures 17 and 18 emphasize $A, M, N t$, and Bi influences on $-f^{\prime \prime}(0)$. Here, skin friction diminishes for $A$ and $M$ are augmented. However, opposite appearances noticed for $N t$ and $\mathrm{Bi}$ enlarged. The attributes of $\mathrm{Bi}, N t, A$, and $\operatorname{Pr}$ interpreted on $-\theta^{\prime}(0)$ are shown in Figures 19-21. These figures confirm that $-\theta^{\prime}(0)$ Nusselt number upsurges subject to augmented in $\mathrm{Bi}, \mathrm{Nt}, \mathrm{A}$, and Pr parameters. Figures $22-25$ explain the impression of magnetic and velocity ratio parameters on streamlines. 


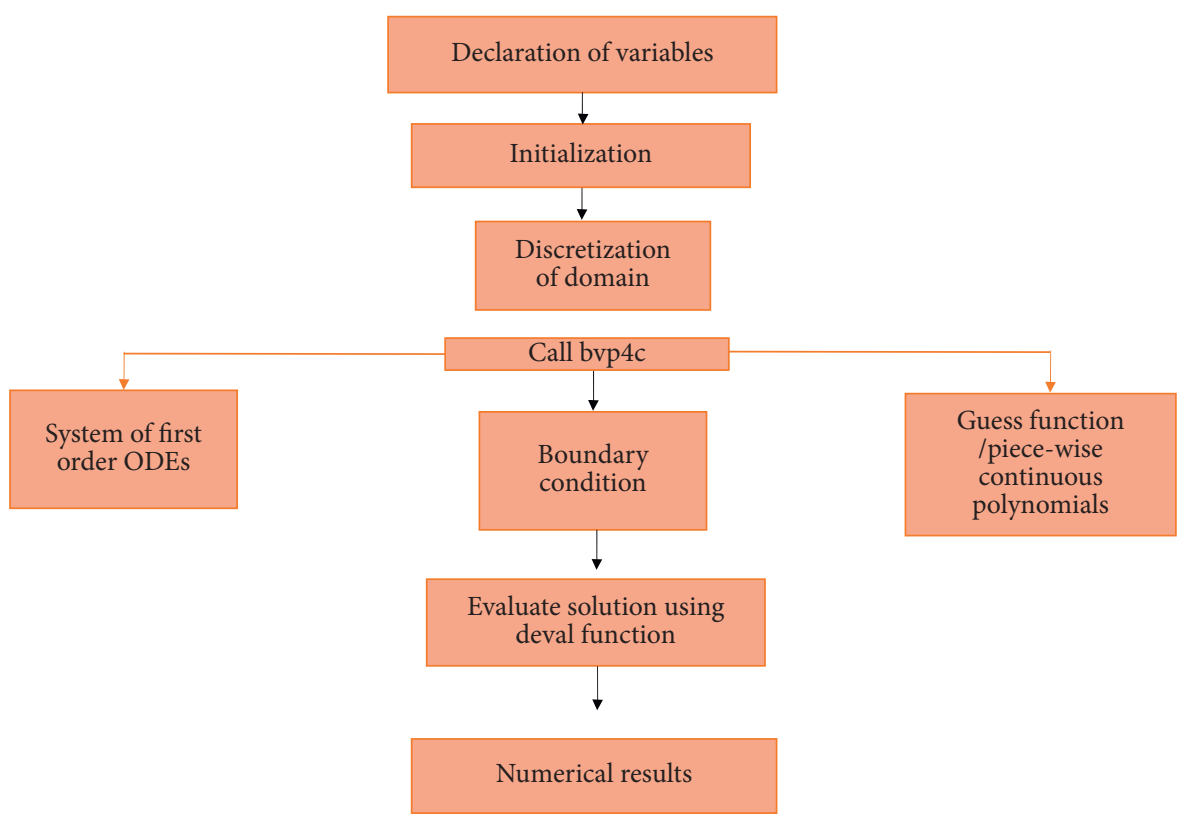

FIGURE 3: Algorithm of bvp4c routine in Mathematica software.

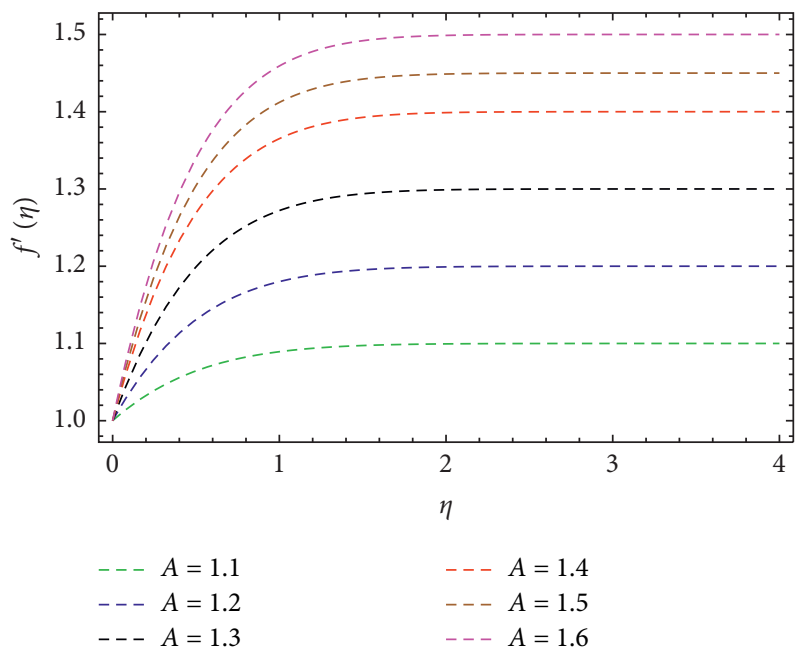

Figure 4: $f^{\prime}(\eta)$ versus $A(A>1)$.

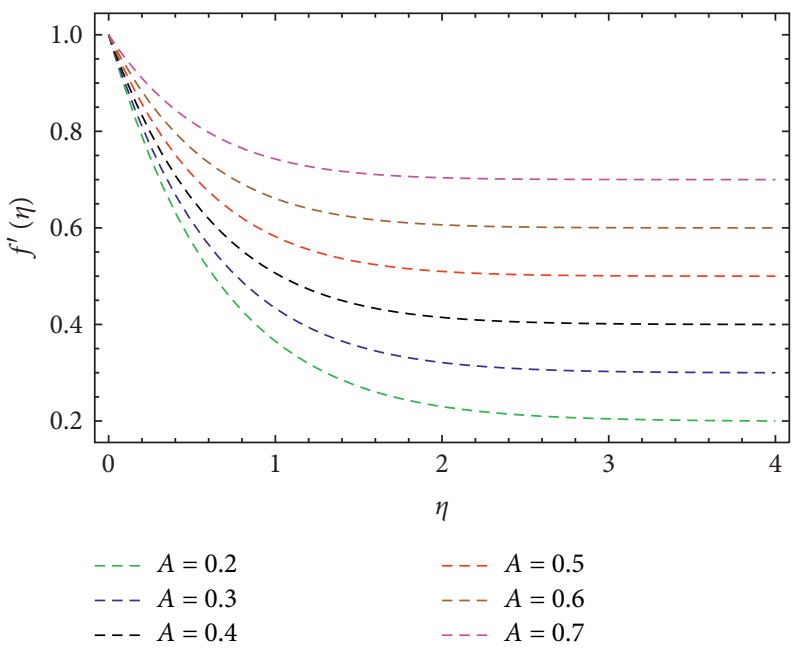

Figure 5: $f^{\prime}(\eta)$ versus $A(A<1)$. 


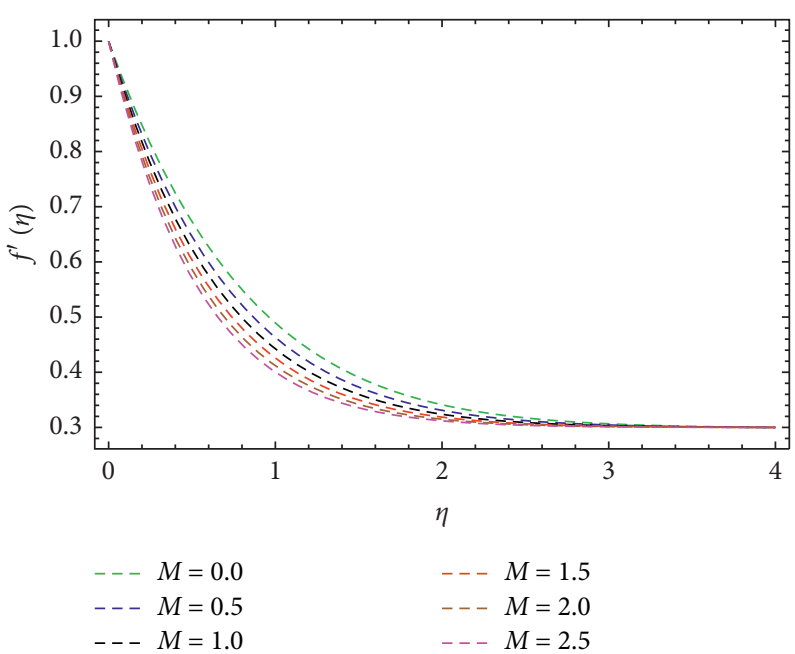

Figure 6: $f^{\prime}(\eta)$ versus $M$.

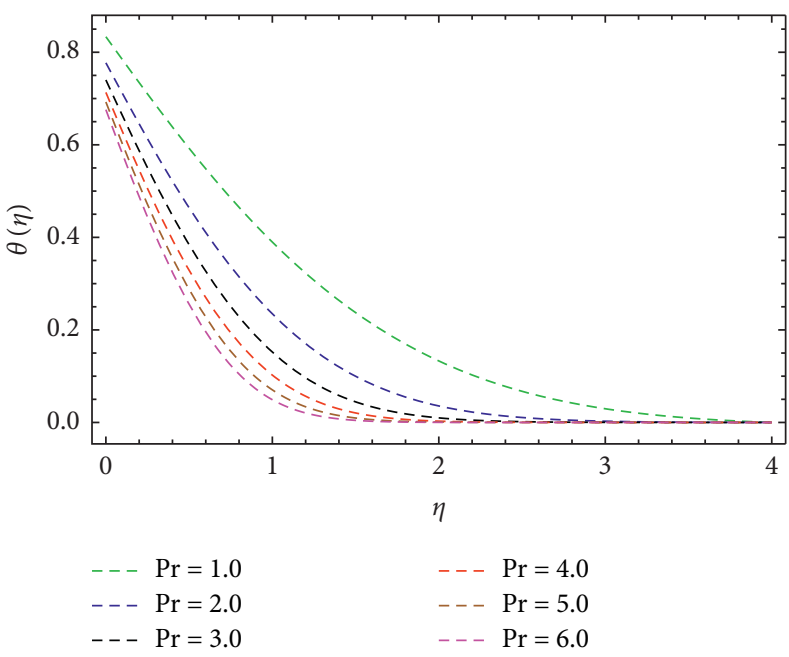

Figure 7: $\theta(\eta)$ versus Pr.

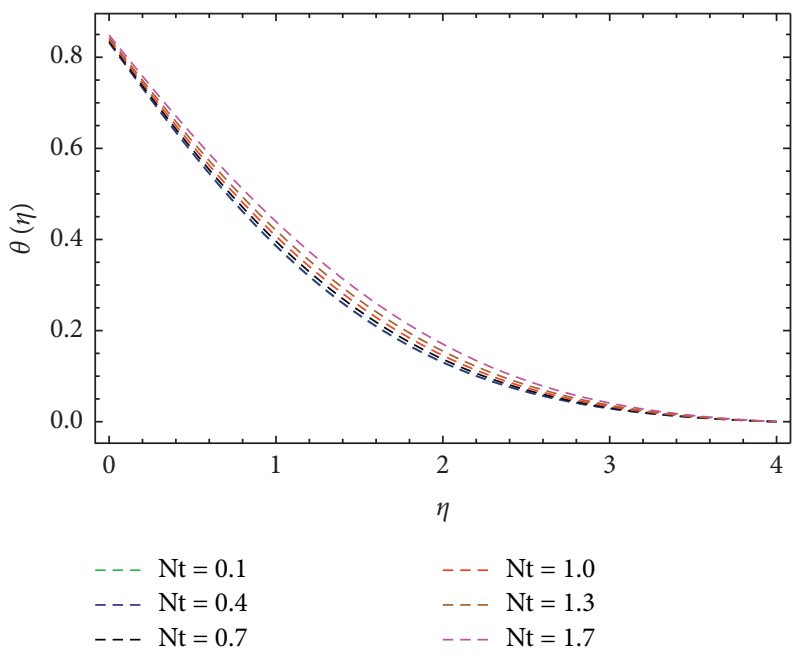

Figure 8: $\theta(\eta)$ versus $N t$. 


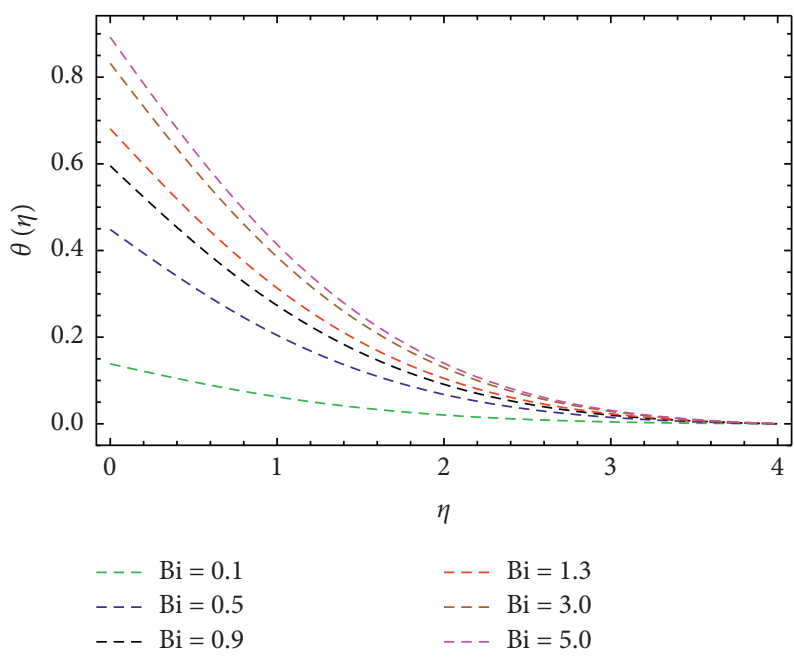

Figure 9: $\theta(\eta)$ versus $B i$.

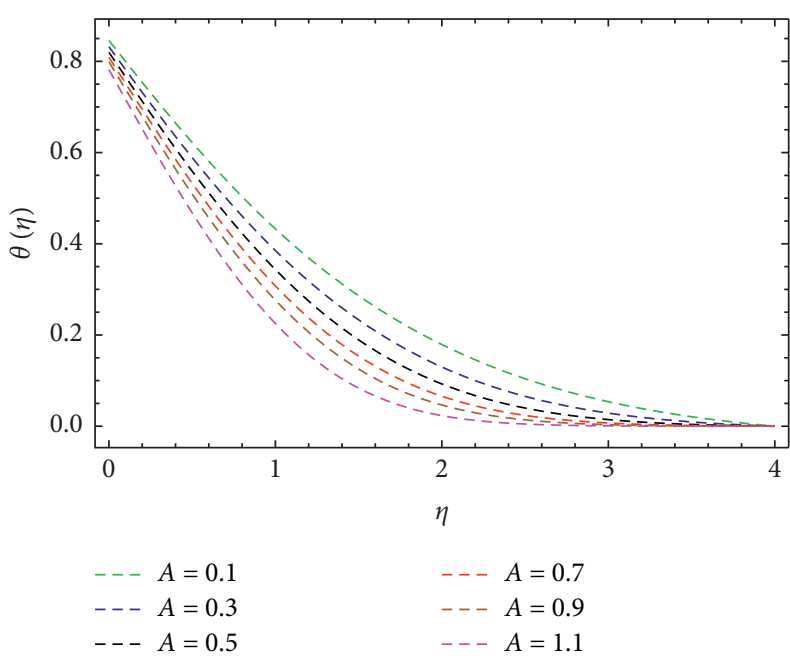

Figure 10: $\theta(\eta)$ versus $A$.

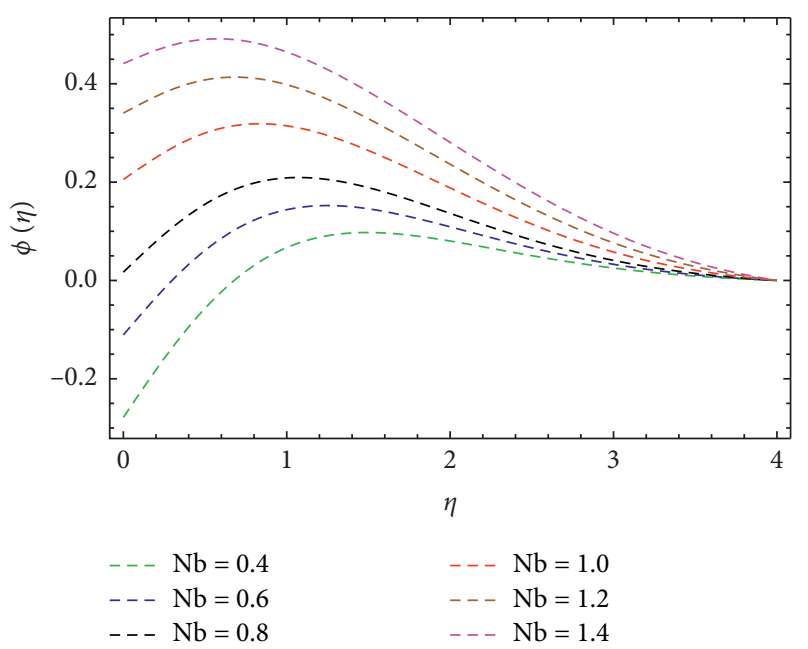

FIGURE 11: $\phi(\eta)$ versus $N b$. 


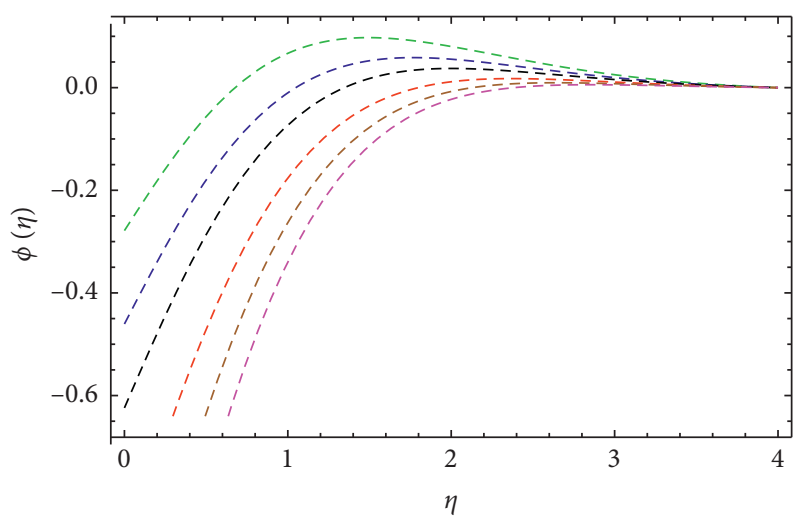

$\begin{array}{ll}--\mathrm{Nt}=0.4 & ---\mathrm{Nt}=0.8 \\ ---\mathrm{Nt}=0.5 & --\mathrm{Nt}=1.0 \\ ---\mathrm{Nt}=0.6 & ---\mathrm{Nt}=1.2\end{array}$

Figure 12: $\phi(\eta)$ versus $N t$.

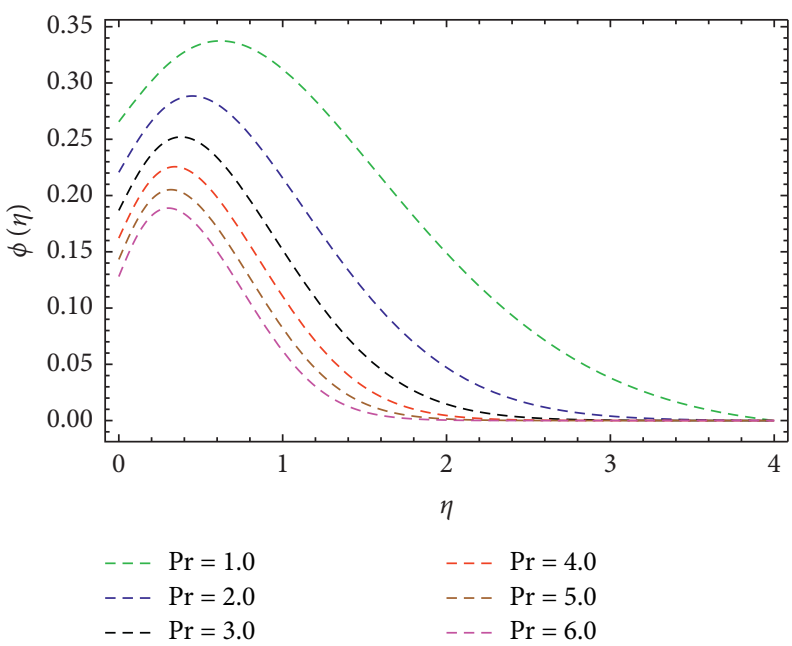

Figure 13: $\phi(\eta)$ versus Pr.

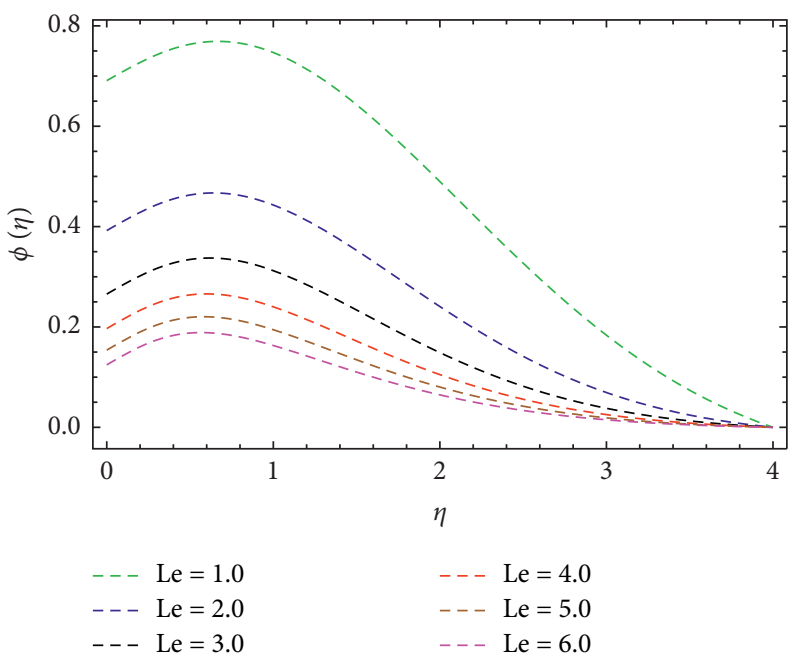

Figure 14: $\phi(\eta)$ versus Le. 


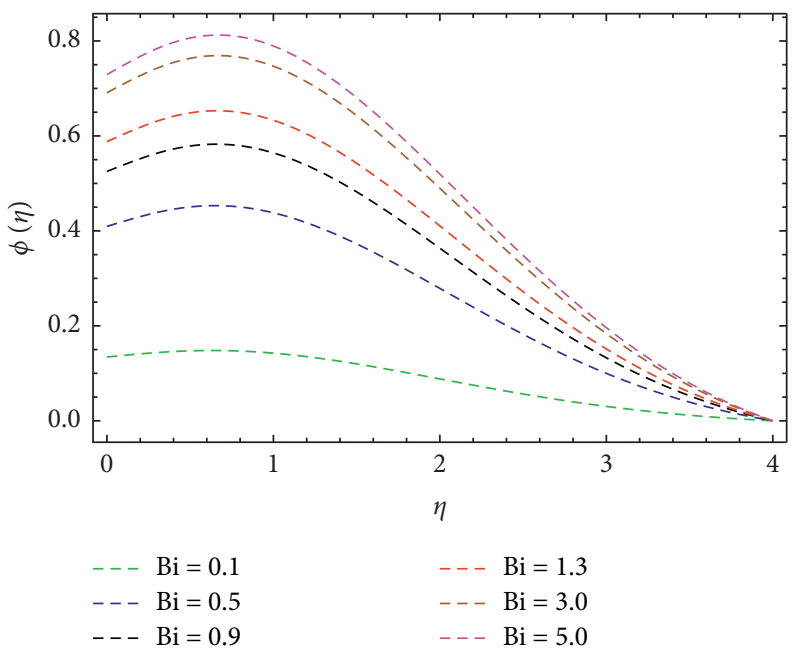

Figure 15: $\phi(\eta)$ versus Bi.

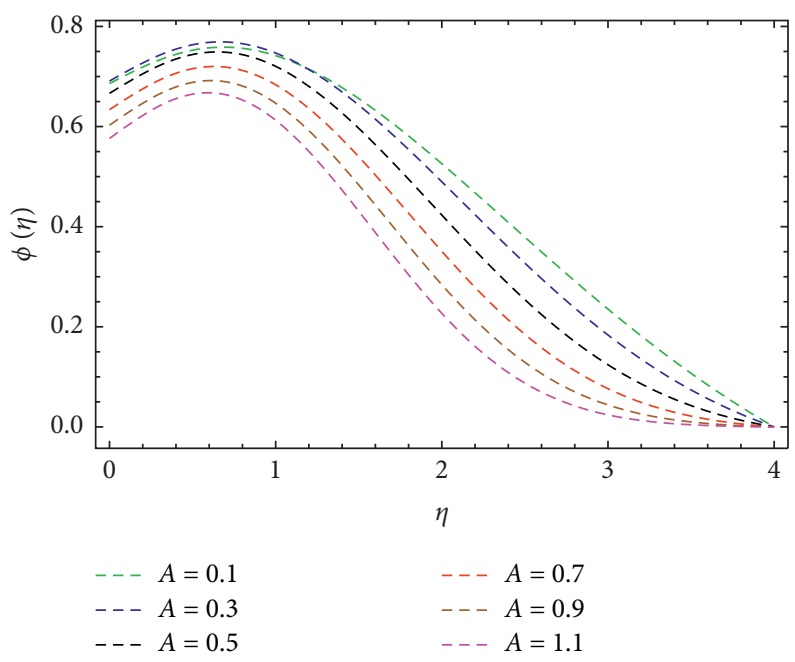

Figure 16: $\phi(\eta)$ versus $A$.

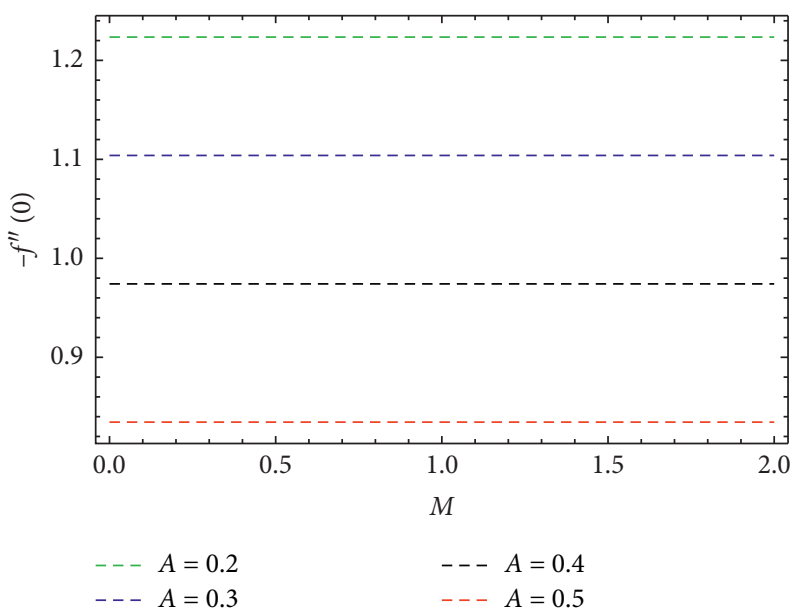

Figure 17: Variation in $-f^{\prime \prime}(0)$ via $A$ and $M$. 


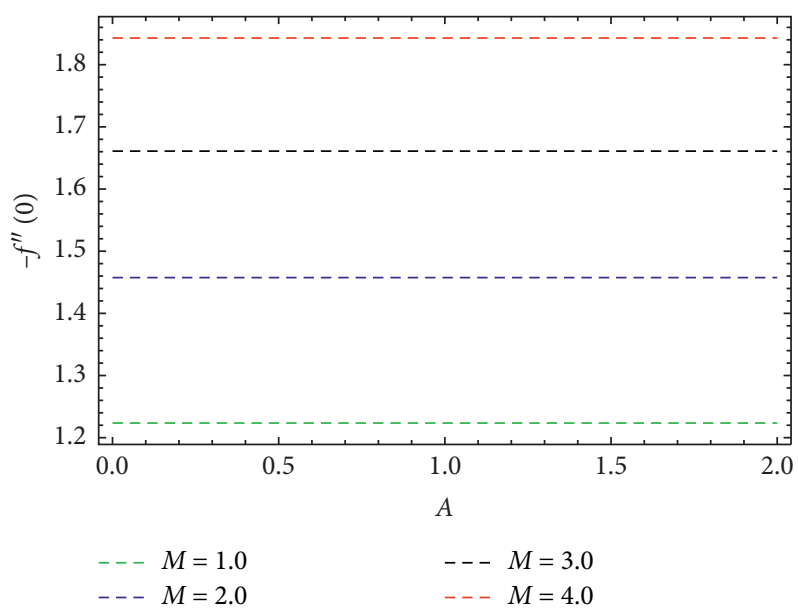

Figure 18: Variation in $-f^{\prime \prime}(0)$ via $M$ and $A$.

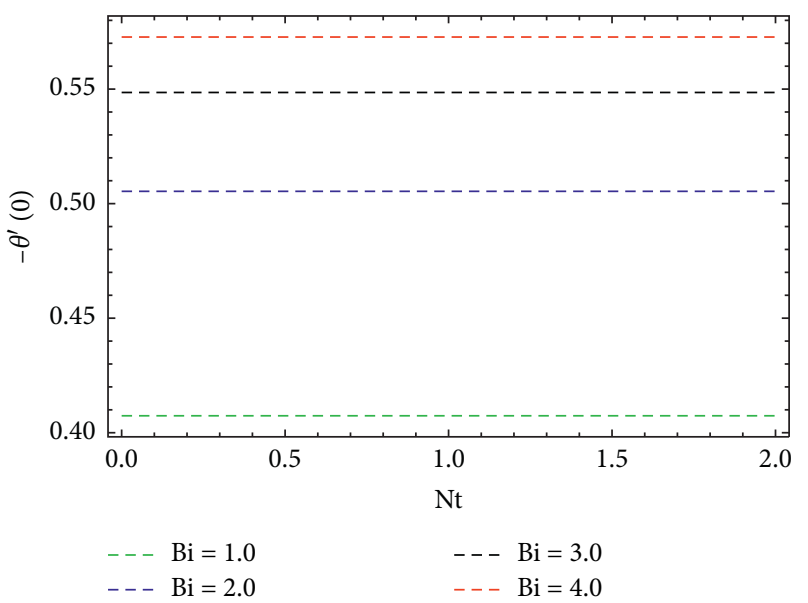

Figure 19: Variation in $-\theta^{\prime}(0)$ via Bi and $N t$.

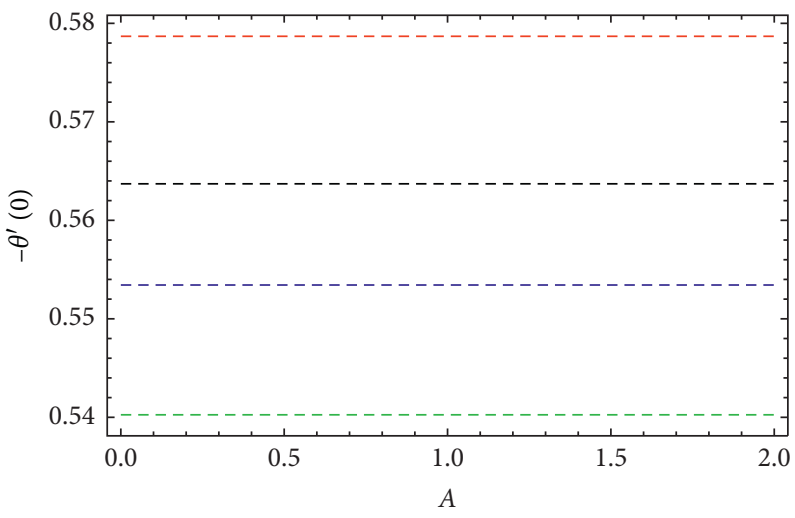

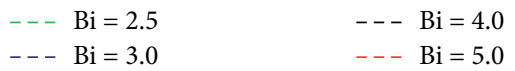

Figure 20: Variation in $-\theta^{\prime}(0)$ via $\mathrm{Bi}$ and $A$. 


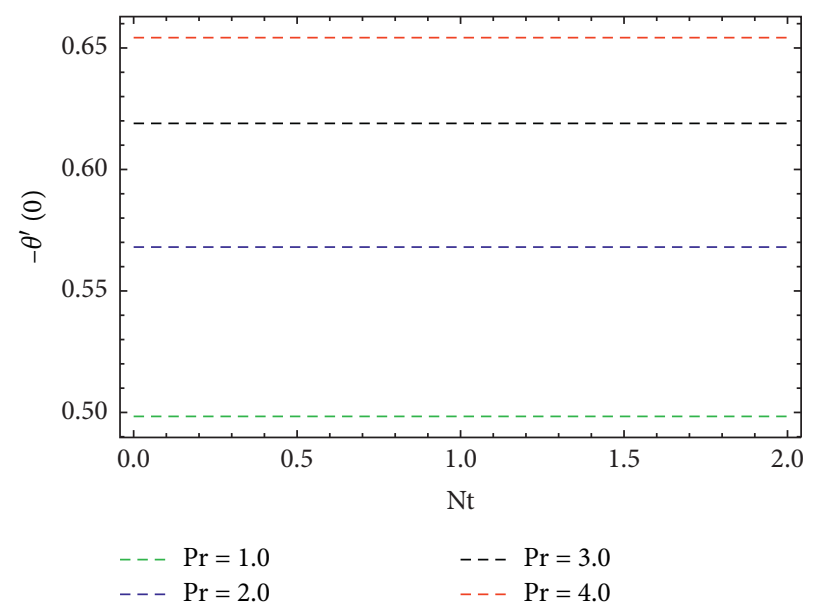

Figure 21: Variation in $-\theta^{\prime}(0)$ via Pr and $N t$.

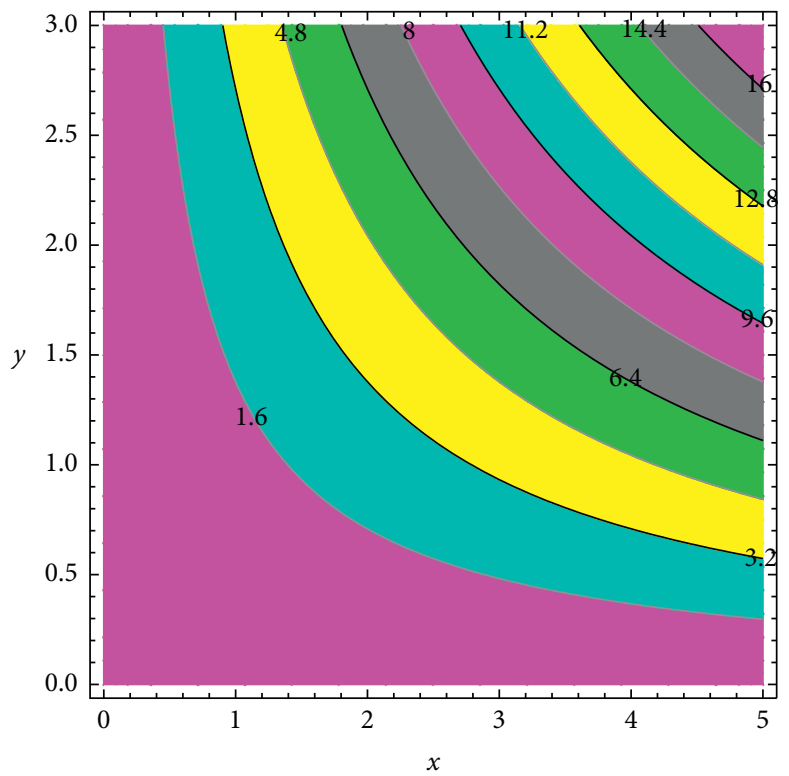

Figure 22: Streamlines for $M=1.0$.

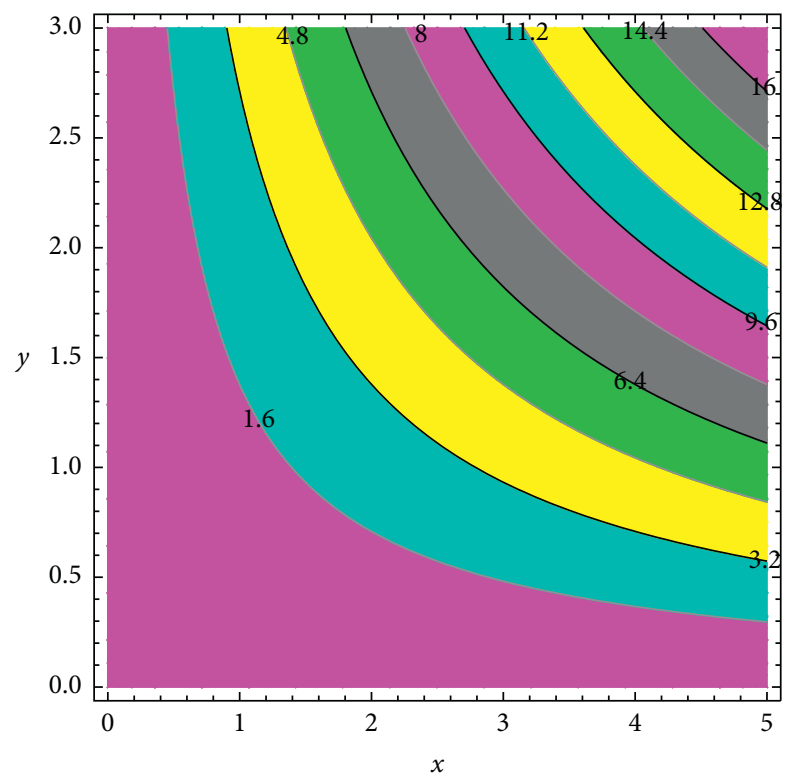

FIGURE 23: Streamlines for $M=10.0$. 


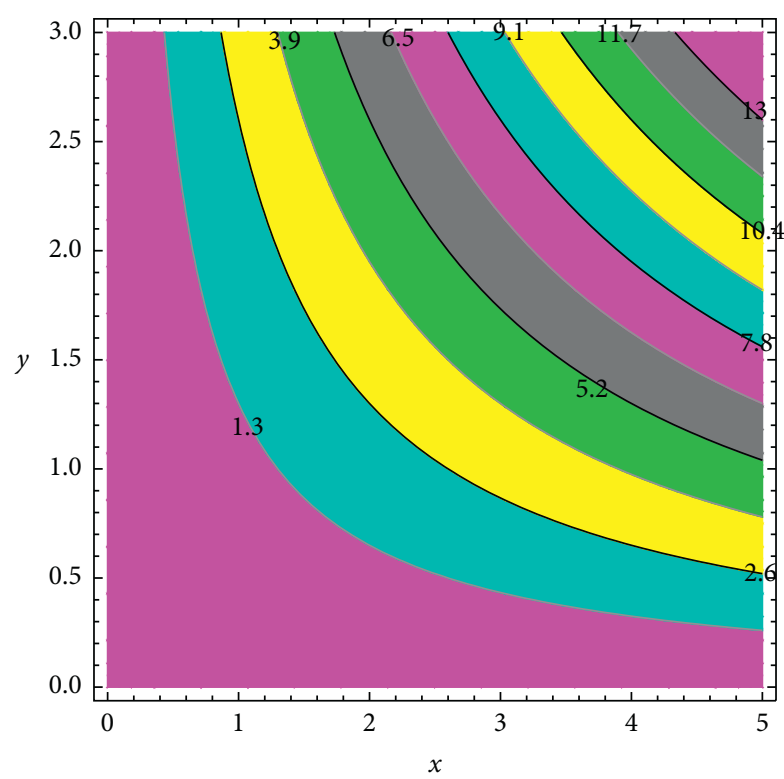

Figure 24: Streamlines for $A=1.0$.

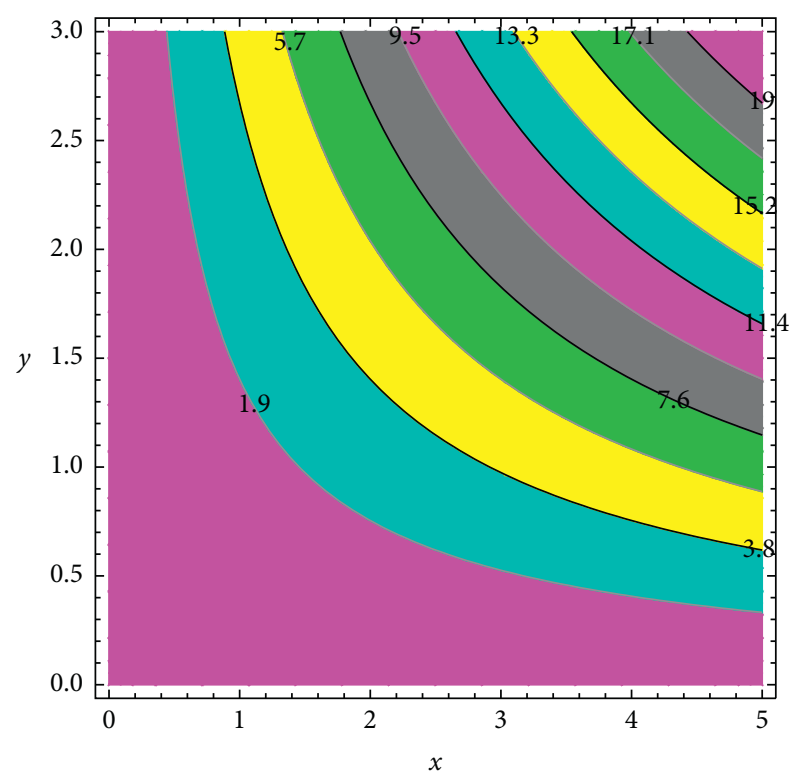

FIgURE 25: Streamlines for $A=10.0$.

\section{Conclusions}

Here, we formulated hydrodynamics stagnation point nanofluid flow over a surface with the magnetic effect and convective boundary condition. Furthermore, heat transportation features subject to viscous dissipation has been discussed. We witnessed the following are the noteworthy points from aforementioned investigation:

We found lower $-f^{\prime \prime}(0)$ when $A$ velocity ratio factor incremented and $-f^{\prime \prime}(0)$ upsurges for a higher magnetic field value

An augmentation in $N b$ and $N t$ yields an opposite report for the solutal $\phi(\eta)$ boundary layer
Larger velocity parameter $A$ and Boit number Bi yields $-\theta^{\prime}(0)$ escalates

An increment in thermal boundary is noticed for higher $N t$ and diminishes for larger Pr values

Both parameters $N b$ and $N t$ yield higher thermal $\theta(\eta)$ field

The solutal $\phi(\eta)$ boundary layer thickness is near stretching sheet negative and zero elsewhere

\section{Data Availability}

The data used to support the findings of this study are included within the article.

\section{Conflicts of Interest}

The authors declare that they have no conflicts of interest.

\section{Acknowledgments}

The authors extend their appreciation to the Deanship of Scientific Research at Majmaah University for funding this work under the project number (RGP-2019-6).

\section{References}

[1] S. U. Choi and J. A. Eastman, Enhancing. Thermal Conductivity of Fluids with Nanoparticles (No. ANL/MSD/CP-84938), Argonne National Lab, Lemont, IL, USA, 1995.

[2] I. Khan, S. Fatima, M. Y. Malik, and T. Salahuddin, "Exponentially varying viscosity of magnetohydrodynamic mixed convection eyring-powell nanofluid flow over an inclined surface," Results in Physics, vol. 8, pp. 1194-1203, 2018.

[3] M. Turkyilmazoglu, "Free and circular jets cooled by single phase nanofluids," European Journal of Mechanics-B/Fluids, vol. 76, pp. 1-6, 2019.

[4] T. K. Nguyen, A. Saidizad, M. Jafaryar et al., "Influence of various shapes of $\mathrm{CuO}$ nanomaterial on nanofluid forced convection within a sinusoidal channel with obstacles," Chemical Engineering Research and Design, vol. 146, pp. 478-485, 2019.

[5] R. Mehmood, R. Tabassum, O. Pourmehran, and D. D. Ganji, "Crosswise stream of hydrogen-oxide $(\mathrm{H} 2 \mathrm{O})$ through a porous media containing copper nanoparticles," International Journal of Hydrogen Energy, vol. 43, pp. 7562-7569, 2018.

[6] H. Park, S. J. Lee, and S. Y. Jung, "Effect of nanofluid formation methods on behaviors of boiling bubbles," International Journal of Heat and Mass Transfer, vol. 135, pp. 1312-1318, 2019.

[7] H. Jang, W. S. Lee, and J. Lee, "Rheological characteristics of non-newtonian GPTMS-SiO2 nanofluids," International Communications in Heat and Mass Transfer, vol. 106, pp. 138-45, 2019.

[8] M. J. Assael, K. D. Antoniadis, W. A. Wakeham, and X. Zhang, "Potential applications of nanofluids for heat transfer," International Journal of Heat and Mass Transfer, vol. 138, pp. 597-607, 2019.

[9] A. Zeiny, H. Jin, G. Lin, P. Song, and D. Wen, "Solar evaporation via nanofluids: a comparative study," Renewable Energy, vol. 122, pp. 443-454, 2019.

[10] S. Nadeem, A. U. Khan, and S. Saleem, "A comparative analysis on different nanofluid models for the oscillatory 
stagnation point flow," The European Physical Journal Plus, vol. 131, p. 261, 2016.

[11] K. Hiemenz, "Die grenzschicht an einem in den gleichformigen flussigkeitsstrom eingetauchten geraden kreiszylinder," Dinglers Polytech, vol. 326, pp. 321-324, 1922.

[12] A. U. Khan, S. Saleem, S. Nadeem, and A. A. Alderremy, "Analysis of unsteady non-axisymmetric homann stagnation point flow of nanofluid and possible existence of multiple solutions," Physica A: Statistical Mechanics and Its Applications, vol. 554, Article ID 123920, 2019.

[13] A. Hussain, S. Afzal, R. Rizwana, and M. Y. Malik, "MHD stagnation point flow of a casson fluid with variable viscosity flowing past an extending/shrinking sheet with slip effects," Physica A: Statistical Mechanics and Its Applications, vol. 553, Article ID 124080, 2020.

[14] R. Mehmood, S. Rana, N. S. Akbar, and S. Nadeem, "Nonaligned stagnation point flow of radiating casson fluid over a stretching surface," Alexandria Engineering Journal, vol. 57, no. 2, pp. 939-946, 2018.

[15] N. P. Moshkin, V. V. Pukhnachev, and Y. D. Bozhkov, "On the unsteady, stagnation point flow of a maxwell fluid in 2D," International Journal of Non-linear Mechanics, vol. 116, pp. 132-138, 2019.

[16] P. Weidman, "Hiemenz stagnation-point flow impinging on a uniformly rotating plate," European Journal of Mechanics-B/ Fluids, vol. 78, 2019.

[17] E. Azhar, Z. Iqbal, and E. N. Maraj, "Viscous dissipation performance on stagnation point flow of jeffrey fluid inspired by internal heat generation and chemical reaction," Thermal Science and Engineering Progress, vol. 13, Article ID 100377, 2019.

[18] N. Abbas, S. Saleem, S. Nadeem, A. A. Alderremy, and A. U. Khan, "On stagnation point flow of a micro polar nanofluid past a circular cylinder with velocity and thermal slip," Results in Physics, vol. 9, pp. 1224-1232, 2018.

[19] N. S. Akbar, Z. H. Khan, and S. Nadeem, "The combined effects of slip and convective boundary conditions on stagnation-point flow of CNT suspended nanofluid over a stretching sheet," Journal of Molecular Liquids, vol. 196, pp. 221-225, 2014.

[20] N. Ijaz, A. Zeeshan, and M. M. Bhatti, "Peristaltic propulsion of particulate non-newtonian ree-eyring fluid in a duct through constant magnetic field," Alexandria Engineering Journal, vol. 57, no. 2, pp. 1055-1060, 2018.

[21] A. Hussain, S. Akbar, L. Sarwar, S. Nadeem, and Z. Iqbal, "Effect of time dependent viscosity and radiation efficacy on a non-newtonian fluid flow," Heliyon, vol. 5, Article ID e01203, 2018.

[22] T. Muhammad, H. Waqas, S. A. Khan, R. Ellahi, and S. M. Sait, "Significance of nonlinear thermal radiation in 3D eyring-powell nanofluid flow with arrhenius activation energy," Journal of Thermal Analysis and Calorimetry, vol. 143, no. 2, pp. 929-944, 2021.

[23] Z. Hussain and T. Muhammad, "Simultaneous influence of hall and wall characteristics in peristaltic convective carbonwater flow subject to soret and dufour effects," Arabian Journal for Science and Engineering, vol. 46, no. 3, pp. 2033-2046, 2021.

[24] T. Muhammad, S. Z. Alamri, H. Waqas, D. Habib, and R. Ellahi, "Bioconvection flow of magnetized carreau nanofluid under the influence of slip over a wedge with motile microorganisms," Journal of Thermal Analysis and Calorimetry, vol. 143, no. 2, pp. 945-957, 2021.
[25] A. Hussain, S. Ghafoor, M. Y. Malik, and S. Jamal, "An exploration of viscosity models in the realm of kinetic theory of liquids originated fluids," Results in Physics, vol. 7, pp. 2352-2360, 2017.

[26] H. B. Da Veiga and J. Yang, "On the energy equality for solutions to newtonian and non-newtonian fluids," Nonlinear Analysis, vol. 185, pp. 388-402, 2019.

[27] K. C. Da Silva, I. De Jesus Da Silva, L. A. Calçada, and C. M. Scheid, "The effect of previous sedimentation on the filtration and mudcake properties of newtonian and nonnewtonian fluids," Powder Technology, vol. 346, pp. 9-16, 2019.

[28] X. Yang, Y. Liang, and W. Chen, “A fractal roughness model for the transport of fractional non-newtonian fluid in microtubes," Chaos, Solitons \& Fractals, vol. 126, pp. 236-241, 2019.

[29] J. Deteix and D. Yakoubi, "Shear rate projection schemes for non-newtonian fluids," Computer Methods in Applied Mechanics and Engineering, vol. 354, pp. 620-636, 2019.

[30] A. S. S. Nadeem, "Metachronal wave analysis for non-newtonian fluid inside a symmetrical channel with ciliated walls," Results in Physics, vol. 7, pp. 1536-1549, 2017.

[31] A. S. S. Nadeem, "Metachronal wave analysis for non-newtonian fluid under thermophoresis and brownian motion effects," Results in Physics, vol. 7, pp. 2950-2957, 2017.

[32] M. Abdolahzadeh, A. Tayebi, and P. Omidvar, "Mixing process of two-phase non-newtonian fluids in $2 \mathrm{D}$ using smoothed particle hydrodynamics," Computers \& Mathematics with Applications, vol. 78, pp. 110-122, 2019.

[33] M. Dejam, "Dispersion in non-newtonian fluid flows in a conduit with porous walls," Chemical Engineering Science, vol. 189, pp. 296-310, 2018. 